\title{
On the Development of Viscous Solvers for Computation of Transient Flows in Turbomachines*
}

\author{
ALEXANDER WIEDERMANN ${ }^{\dagger}$, KAZUYOSHI MIYAGAWA and TSUYOSHI EGUCHI \\ Turbomachinery Research Laboratory, Takasago Research and Development Center, Mitsubishi Heavy Industries Ltd., \\ 2-1-1 Shinhama, Arai-cho, Takasago, Hyogo Prefecture, 676 Japan
}

(Received in final form 7 July 1998)

\begin{abstract}
This paper focuses on development and validation of a viscous solver for the computation of unsteady flows in turbomachinery blade rows and stages consisting of rotors and stators. The code has been evolved from steady-state single flow solvers developed by Wiedermann based on time-marching finite difference schemes. A two-equation eddy viscosity model is applied, and the wall boundary conditions are determined by the $y^{+}$-distance of the first grid line away from the wall. For the solution of transient flow fields the original time-stepping algorithm is replaced by a time-accurate scheme.

The emphasis of the code validation will be on blade-row interaction in a complete turbomachinery stage. A 3-D example will be discussed and those parameters evaluated which are important for actual blading design.
\end{abstract}

Keywords: Unsteady Navier-Stokes computation, Blade-row interaction, Code development, Validation, Turbulence models

\section{INTRODUCTION}

The recent development of fast and powerful workstations has favoured application of fully 3-D Navier-Stokes solvers to the design of new turbomachinery blade rows (Miyawaki et al., 1996). With respect to the complexity of the flow problem involved accuracy has reached a level which is acceptable for the designer (Rhie et al., 1994). In particular the computation of details of turbulent boundary layers and flow regimes dominated by secondary flows in a single row of a turbomachine is well established, and the codes can be run efficiently on either work stations or supercomputers (Dawes, 1988; Wiedermann, 1995).

Beyond the single-row flow analyses the numerical investigation of a turbomachinery stage consisting of rotor and stator is inevitable for the prediction of turbomachinery blade row matching in multi-stage machines. As fully time-dependent

\footnotetext{
* This paper was originally presented at ISROMAC-7.

${ }^{\dagger}$ Corresponding author. Tel.: +81 (794) 45 6759. Fax: +81 (794) 45 6947. E-mail: arw@wb.trdc.mhi.co.jp.
} 
solutions of the complex 3-D turbulent flow for the entire flowpath in turbines and compressors still exceed the capacity of even the largest supercomputers available, alternative approaches for the interaction of stationary and rotating blade rows have been developed (Adamczyk, 1985). In general, the coupling of the individual blade rows is accomplished by so-called mixing planes where pitch-averaged flow quantities are transferred across the moving interfaces (Denton, 1992; Arnone and Benvenuti, 1994). In strongly coupled blade rows characterized by tight axial clearances enforcement of circumferentially uniform flow distributions affects the accuracy of the results and the blade pressure distributions, and may cause numerical problems (Denton, 1992).

The approaches discussed above are, nevertheless, essential design tools and offer information about global rotor-stator interaction effects at relatively low computational costs. However, for the structural design of turbomachinery components transient boundary conditions have to be extracted from CFD-analysis to predict aeroelastic phenomena. Recently, Eguchi and Wiedermann (1995) developed a 2-D Navier-Stokes solver for the analysis of stalled and unstalled flutter prediction of compressor and steam turbine blade sections. They introduced body-fitted meshes which are self-adapted to the motion of the blades. For the prediction of aeroelastic stability charts results were obtained for various interphase angles which were realized by increasing the number of blade passages. Other 2-D unsteady multi-passage solvers have been developed to predict propagation of rotating stall cells in axial compressor sections covering the coupling of rotor and stator flow fields (Kato et al., 1995). A multi-row multi-passage solver developed by $\mathrm{He}$ (1993) simultanuously includes integration schemes for the governing equations of structural and fluid mechanics and enables prediction of fluid-structural interaction.

The topic of this contribution is the 3-D investigation of rotor-stator interaction in a compressor stage. Gusts originated by wakes of adjacent passing blade rows have a severe effect on structural excitation of the blades. Moreover, the loss mechanism in the blade rows is influenced by the mixing of wakes with patches of strong turbulent intensities and their passing through the following blade row (Hodson et al., 1992). For these analyses, several computer codes have been developed, e.g. Gallus et al. (1994) and Rai (1987). Basic research work is conducted with experimental and numerical investigations to describe the effect of artificially produced wakes on turbomachinery blade rows which offer a useful framework for code verifications (Cho et al., 1993). From the designer's viewpoint, studies of predicted flow topologies in an axial compressor stage by Dawes (1994) are of particular interest and can be carefully utilized for the improvement of current designs.

\section{MOTIVATION AND SCOPE OF THE PRESENT RESEARCH}

Reviewing the current state of the art of transient flow solvers one finds that excessively large running times and computational costs prevent them from becoming more frequent design tools. Moreover, it is difficult to calibrate 2-D and 3-D unsteady Navier-Stokes solvers, because the measurement of time-dependent flow parameters itself is and will remain a matter of actual research, e.g. Hodson et al. (1992), Gallus et al. (1994). On the other hand, numerical studies as those by Dawes (1994) provide more understanding of the complex physics of technical flows. With this thought in mind, the authors decided to extend an existing 3-D NavierStokes solver developed by Wiedermann (1995) for steady-state 3-D flow fields in single turbomachinery blade rows for the computation of transient flows. The aim of the projected numerical studies of time-dependent fields is the systematic study of the impact of jet-wake gusts on the development of the shear layer along the downstream blades as well as to establish a numerical tool for the determination of vibrational forces on the blade rows due to rotor-stator interaction. 


\section{OUTLINE OF THE FLOW SOLVER}

\subsection{The Numerical Scheme}

The newly developed unsteady flow solver is an extension of a steady-state 3-D Navier-Stokes code developed by Wiedermann (1995). To cover flows with transonic regions the equations are given in a conservative formulation. Spatial discretization is done with a central finite difference scheme in a body-fitted coordinate system. Time integration is performed by a three stage explicit Runge-Kutta scheme, and the maximum allowable time step size is, therefore, restricted by the smallest computational cell according to the Courant-Friedrichs-Levy stability criterion. Stability of the solution is maintained with a blend of 2nd and 4th order differences. High-aspect ratios of the computational cells are compensated by balancing the spectral radii for each individual spatial direction in the transformed numerical plane.

\subsection{The Turbulence Model}

For the modelling of the turbulent flow a $k-\epsilon$ two equation model is applied. Although it is more elaborate than the well-known algebraic BaldwinLomax model it has been preferred by the authors because one of the objectives of the current research is the study of the interaction of turbulent wakes with shear layers of the downstream blade row. Thus, an algorithm has to be chosen which supports convection of turbulent vorticity and eddies after they were shed from the trailing edge (Hodson et al., 1992; Cho et al., 1993).

Since the allowable time step size for the explicit time-marching scheme applied is restricted by the size of the smallest cells, in general the turbulent boundary layer cannot be resolved down to the wall if the time increments shall remain large enough for a practical computation. Thus, a fit to the logarithmic velocity profile has been done for the computational cell next to the wall. For the grid points adjacent to wetted surfaces the turbulent boundary layer coordinate $y^{+}$, given by

$$
y^{+}=\frac{u_{\tau} \rho y}{\mu}
$$

where $u_{\tau}$ means friction velocity, $\rho$ density, $\mu$ the dynamic viscosity and $y$ the normal distance to the wall, is about $30-50$ in average which is an acceptable range for the application of wall functions. The constants of the $k-\epsilon$ model are adjusted to a low-Reynolds number model by Chien (1982). Therefore, the actual wall boundary conditions are controlled by the local values for $y^{+}$, and the no-slip boundary conditions are automatically applied wherever $y^{+} \leq 10$.

\subsection{The Computational Mesh}

For the transonic rotor-stator arrangement studied in this paper, Fig. 1, body-fitted computational meshes are used which are non-overlapping at the gliding planes between the stator and rotor sections in a block-structured arrangement. A typical blade-to-blade section is shown in Fig. 2 .

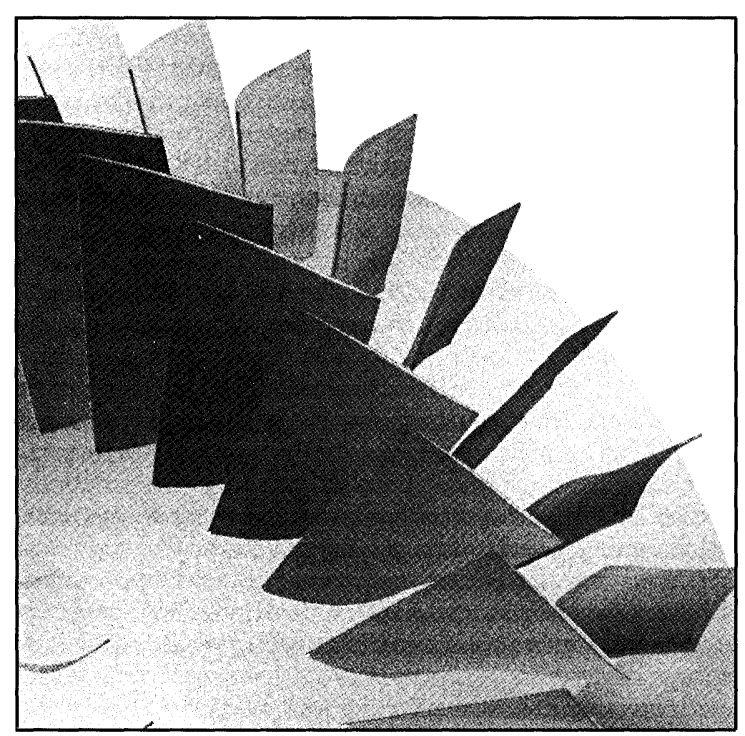

FIGURE 1 Single stage axial compressor tested at DLR, Germany, as reference case. Blade counts: Rotor 28 blades, Stator 31 vanes; Design pressure ratio: 1.51; Choke mass flux: $m=17.58 \mathrm{~kg} / \mathrm{s}$ (Dunker, 1983; Dunker et al., 1983). 


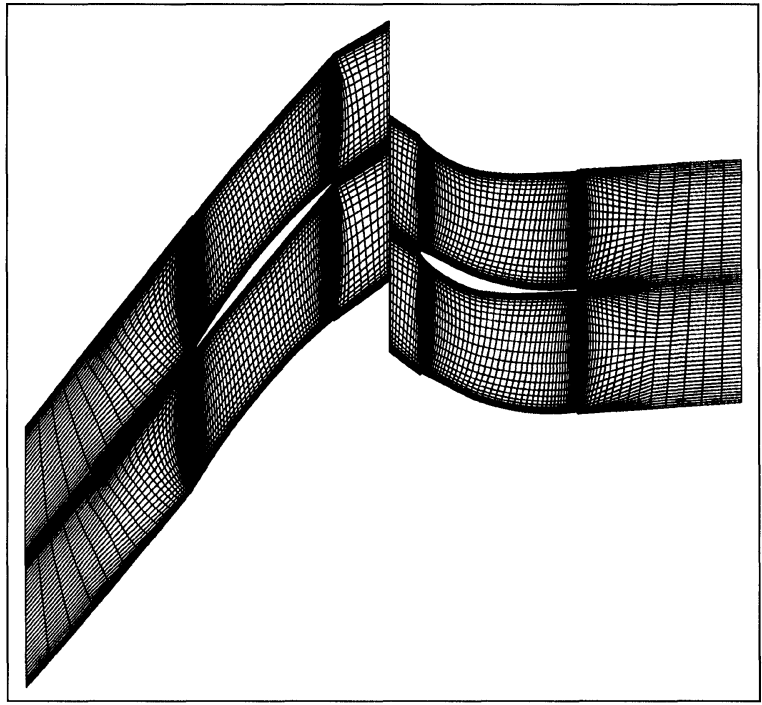

FIGURE 2 Computational mesh for the unsteady analysis at mid span. Rotor: $110 * 35 * 39$ nodes; Stator: $90 * 35 * 39$ nodes.

The meshes are set up with an algebraic meshgeneration system. The computational mesh for our analysis was built of $110 \times 35 \times 39$ grid nodes for the rotor and $90 \times 35 \times 39$ nodes for the stator. At the rotor-stator interface planes flow variables are transferred between the moving domains at each time step. To accommodate the requirements of the computation of near-wall terms for the turbulence models such as the boundary layer coordinate $y^{+}$ the mesh was made as quasi-normal as possible as large skewness has an unfavourable effect on the accuracy of the results. At the inlet and exit sections of the computational domain the mesh is extended to avoid undesirable interactions with the boundary conditions. As a consequence, the boundary conditions have to be moved away from the traverse planes along the estimated streamlines applying simple axisymmetric Euler relations.

\section{VALIDATION OF THE SOLVER}

In this chapter the validation of the 3-D unsteady solver will be discussed. For this purpose a rotorstator configuration will be considered which was investigated by Dunker (1983) and Dunker et al.
(1983). Their single-stage transonic test compressor was designed for a stage pressure ratio of 1.51 and a choke mass rate of $17.58 \mathrm{~kg} / \mathrm{s}$. The experimental results are derived from detailed LDV-measurements and published for several operating conditions. Also investigations of the transient flow field were carried out within the stator vane row (Dunker, 1983) which are used by the authors to validate the transient solutions of the solver. Figure 1 shows a picture of the arrangement consisting of a transonic rotor with 28 blades and a stator with 31 Controlled Diffusion Airfoil-type vanes.

\subsection{Notes on the Runs with the Time-dependent Solver}

A serious problem is the different blade count of the rotor and the stator which must be represented by an equivalent number of passages to enable the application of periodic boundary conditions at the circumferential boundaries of the computational domain in the vaneless regions ahead and downstream of the vaned passages. For the current geometry, only a block-structured mesh with 28 passages for the rotor flow field and 31 for the stator would be the exact computational model to simulate all details of the transient phenomena. This is beyond the computer capacity available and, therefore, a simplified model has to be built for the present analysis. Here, an equal blade count was achieved by reducing the number of stator vanes from 31 to 28 which enables an efficient analysis with only one passage for each row. As a change in the blade count of the transonic rotor would have a stronger effect on the rotor performance than the decrease of stator vanes the current assumption can be accepted as an engineering model. However, it must be pointed out that the stator solidity was not adjusted to the new operating condition, and as a consequence experimental and numerical results for the stator have to be compared with great care.

One blade passing period was divided into 1,000 time steps, and a periodic solution could be achieved after about five passing cycles if a steadystate solution was assumed as an initial guess. 


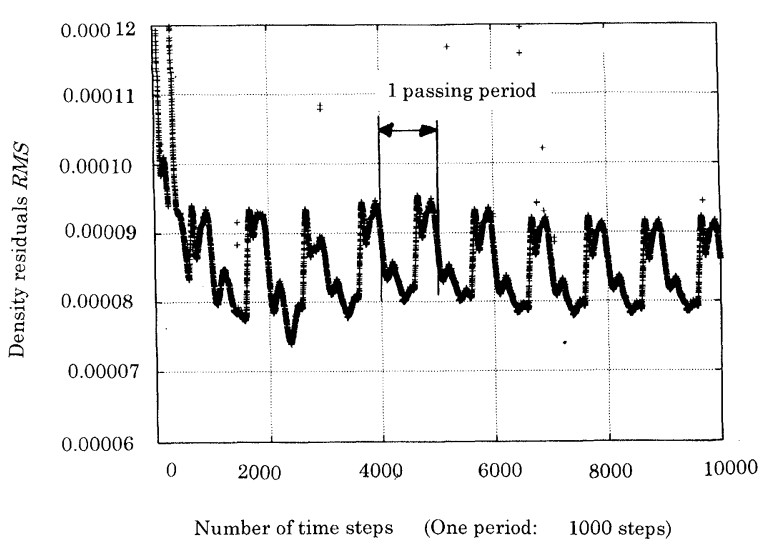

FIGURE 3 Density residuals of the transient analysis.

Typical computational times are about $1 \frac{1}{2}$ days on a workstation for 10 cycles with a total of 10,000 time steps. The initial guess for the computation were either the flow distribution of another operating point or the results of a steady-state analysis with the same solver running in the time-dependent mode on the identical mesh. For this analysis the boundary conditions at the gliding plane between rotor and stator domains were replaced by a circumferential mixing plane treatment which results in circumferentially uniform distributions of some of the flow variables.

For one case the density residuals are shown in Fig. 3. Global blade force histories serve as additional convergence criteria and will be discussed in Chapter 4.4.

\subsection{Evaluation of Time Averaged Results}

For the evaluation of 3-D Navier-Stokes solvers applied to turbomachinery flow fields the comparison of computed and measured averaged quantities at the inlet and outlet planes is of crucial importance for the application of the solver in a design system. Here, the averaged flow variables of the unsteady solver (Case 1) are compared against experimental data (Dunker et al., 1983), the results of the steady-state analysis with mixing planes which was done prior to the unsteady analysis to provide the initial conditions (Case 2), and the computation with the single row 3-D solver by the author (Case 3). For the last case the computational meshes consist of $127 \times 49 \times 59$ grid nodes in axial, pitchwise and spanwise directions for the rotor and $127 \times 49 \times 49$ grid points for the stator. This reference computation was done with the original blade count of the stator. Unlike the unsteady analysis the boundary layer was fully resolved, and the mesh was clustered along the wetted surfaces to achieve sufficiently small values of $y^{+}$for the first couple of grid points away from the wall. During the computation the boundary conditions at the interface between rotor and stator are updated after every other 10th time step by comparing the spanwise distributions of flow variables in the individual domains to achieve a coupling of the row-by-row solutions.

Spanwise distributions of the mass-averaged quantities at the inlet and the exit planes of the rotor are shown in Fig. 4. As mentioned above, the graphs contain the reference results with the fine mesh (Case 3), a multi-stage analysis with the mesh shown in Fig. 2 and a snap-shot of the transient flow field. The agreement between all the cases is fairly good for the rotor flow field, and obviously the coarser mesh with the match to the logarithmic velocity profiles for the first point away from wetted surfaces for the transient solver seems to be justified. However, near the tip the total pressure profiles are underpredicted with the coarser meshes especially for the multi-stage analysis (Case 2). Here, the spanwise distributions of the flow quantities are obviously affected by the mixing plane which enforces circumferentially uniform boundary conditions at the interface between rotor and stator due to the steady-state analysis.

The spanwise distributions for the stator flow field show stronger discrepancies between the results where obviously the quality of the solutions depends on the resolution of the endwall boundary layer, Fig. 5. Both, the multistage analysis with mixing planes (Case 2) and the transient analysis overpredict the effect of the tip clearance vortex on the stator flow field which could not be confirmed by experiments. The high loss level of the 

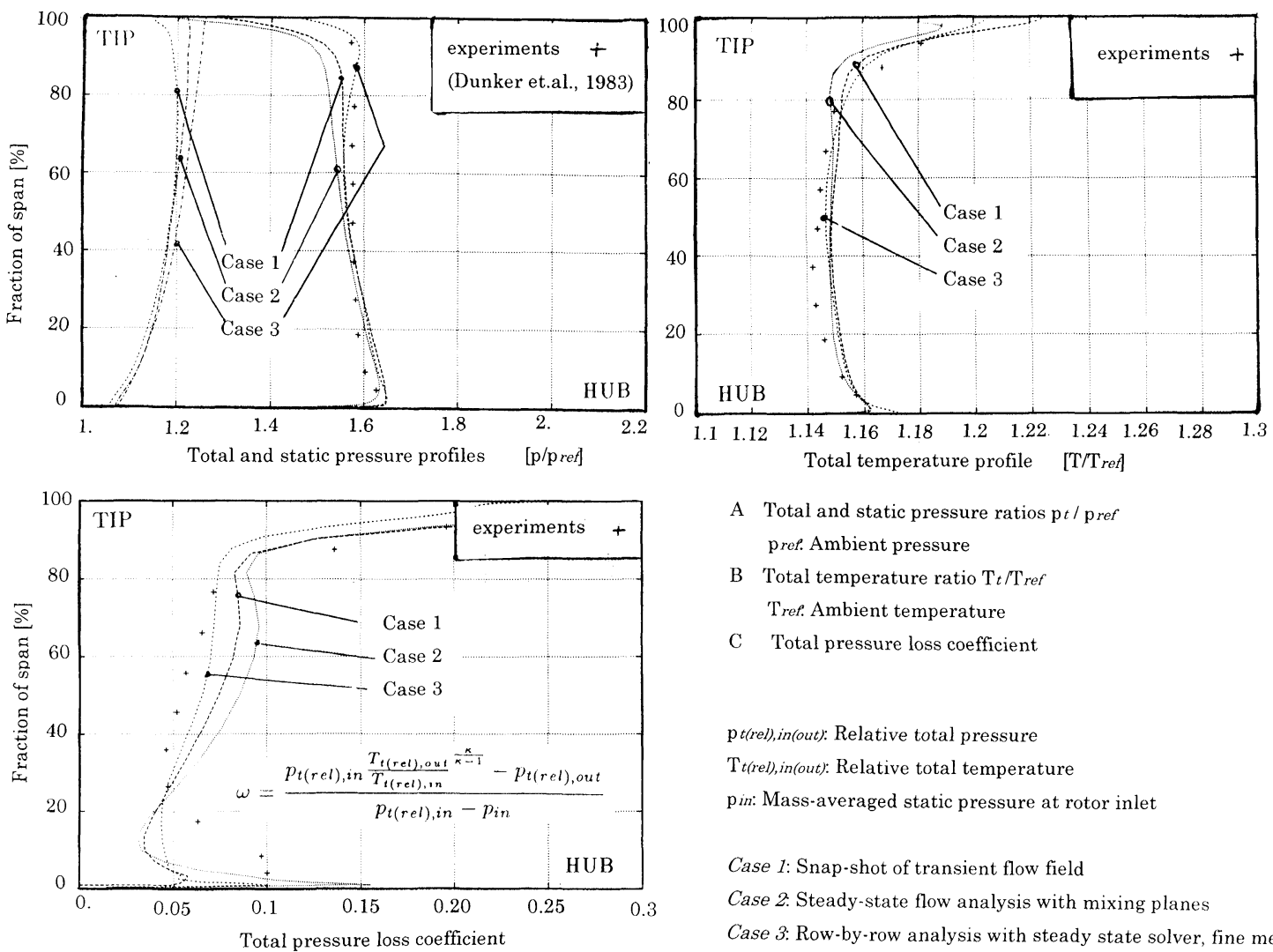

A Total and static pressure ratios $\mathrm{p} t / \mathrm{p}$ ref pree. Ambient pressure

B Total temperature ratio $\mathrm{T} t / \mathrm{T}$ ref Tref. Ambient temperature

C Total pressure loss coefficient

$\mathrm{p}$ t(rel), in(out): Relative total pressure

$\mathrm{T} t(r e l)$, in (out): Relative total temperature

pin: Mass-averaged static pressure at rotor inlet

Case 1: Snap-shot of transient flow field

Case 2. Steady-state flow analysis with mixing planes

Case 3: Row-by-row analysis with steady state solver, fine mesh (Wiedermann, 1995)

FIGURE 4 Comparison of mass-averaged flow quantities at the rotor exit plane

multistage analysis are caused by the numerical production of entropy at the mixing plane and the deficit of total pressure compared with the experiments. One source of the discrepancies might be in the change of the stator vane counts. For the time being, no analysis to evaluate the effect of the different solidities on the stator flow field results has been done.

\subsection{Transient Flow Field Results}

In contrast with steady-state results the evaluation of the time-dependent solutions is much more difficult because only a limited number of measured information about the transient flow fields is available. Therefore, the verification of the solver must partly rely on the capabilities to predict timeaveraged results properly. In addition, time-dependent flow fields will be validated more or less qualitatively, and it shall be demonstrated that the present solver is capable to predict at least trends of the rotor-stator interaction in accordance with the measured results.

Figure 6 shows the results of the isentropic Mach number distributions for the mid span section of the rotor and stator airfoils at three different rotor settings. The blade pressure distribution of the rotor is more strongly affected at the suctions side. On the other hand the time dependency of the flow is more pronounced at the pressure side of the stator, which is due to the movement of the wake sheets through the passages. 

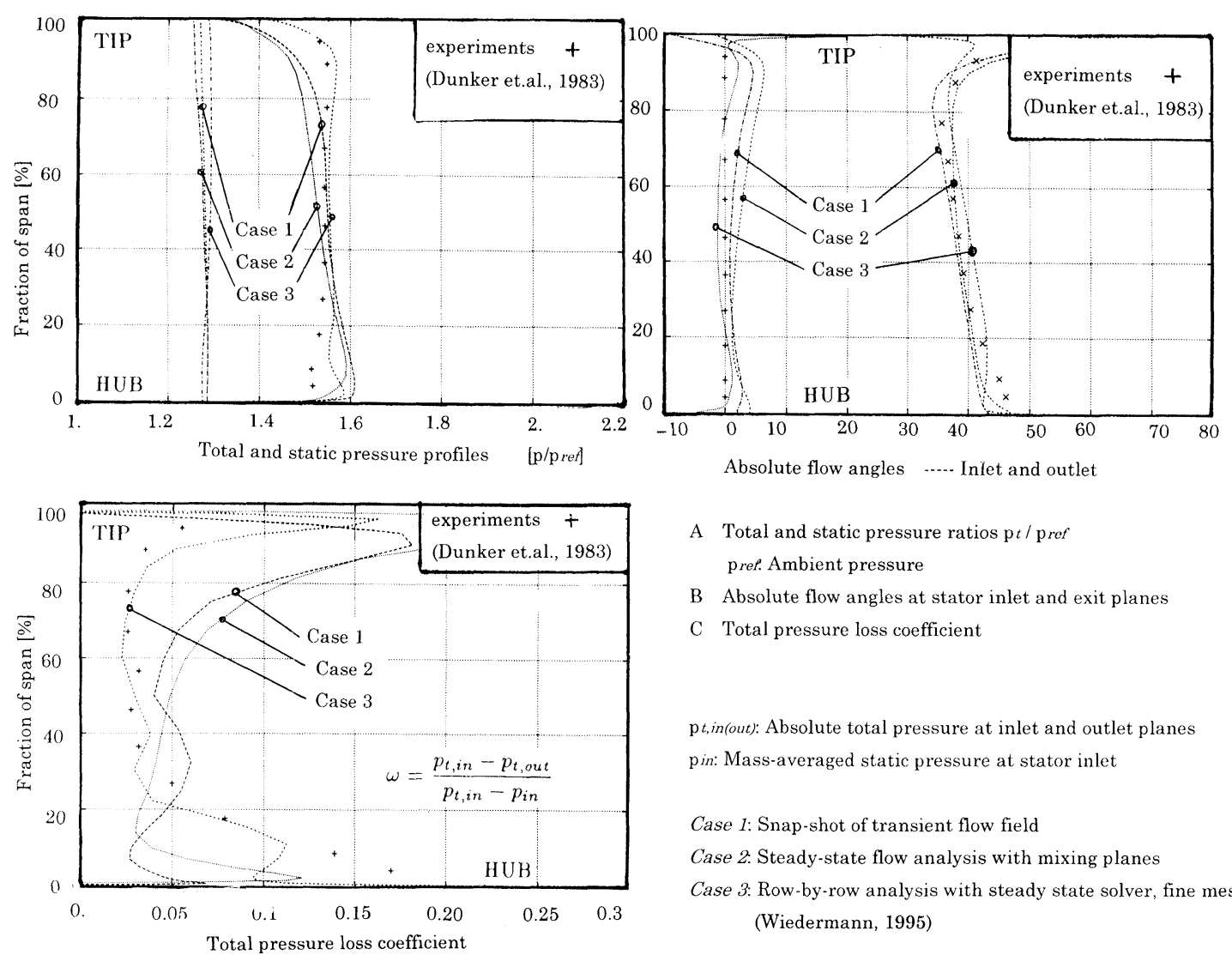

A Total and static pressure ratios $\mathrm{p} t / \mathrm{p} r e f$ pref. Ambient pressure

B Absolute flow angles at stator inlet and exit planes

C Total pressure loss coefficient

$\mathrm{p} t$,in(out): Absolute total pressure at inlet and outlet planes pin: Mass-averaged static pressure at stator inlet

Case 1: Snap-shot of transient flow field

Case 2. Steady-state flow analysis with mixing planes

Case 3: Row-by-row analysis with steady state solver, fine mesh (Wiedermann, 1995)

FIGURE 5 Comparison of mass-averaged flow quantities at the stator inlet and exit planes.
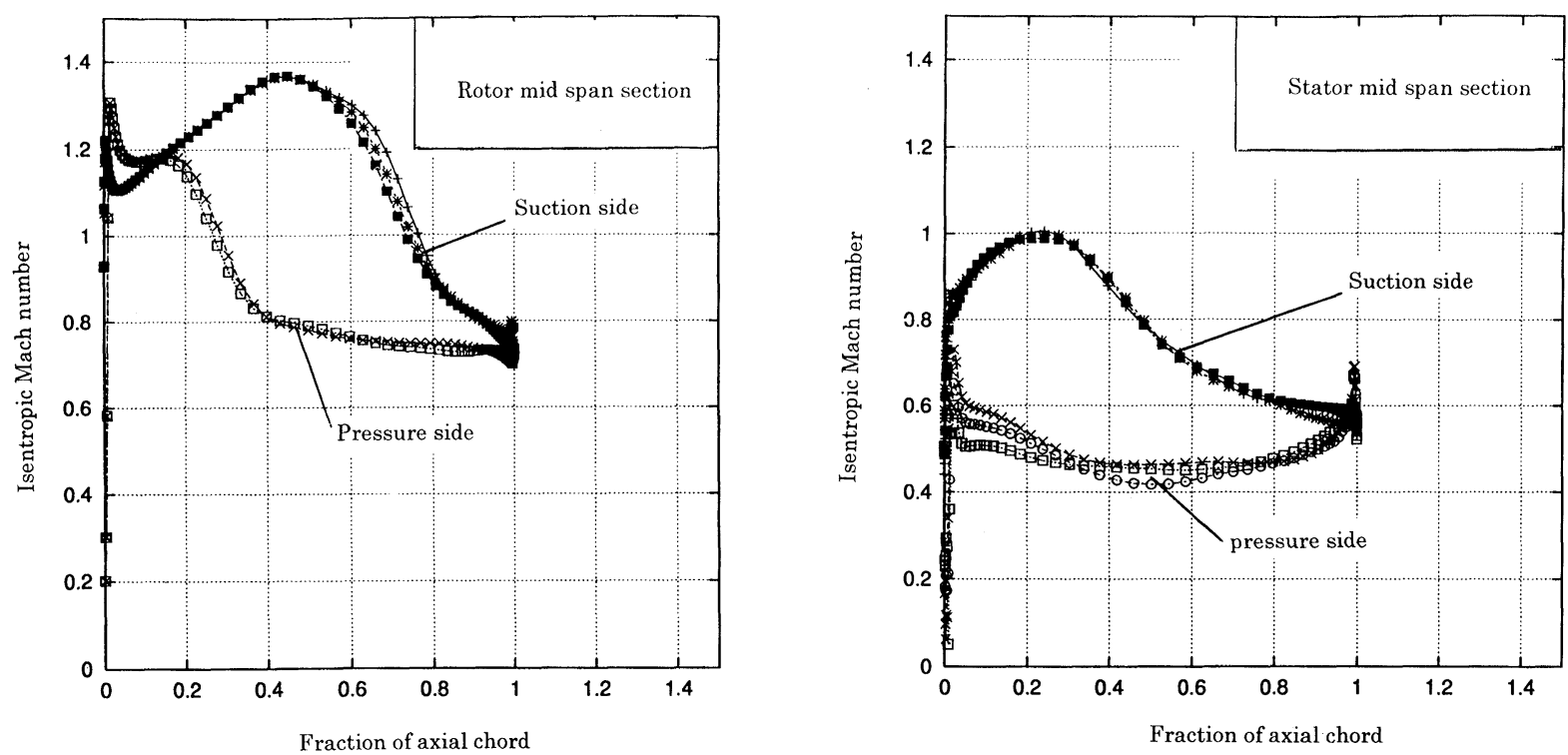

FIGURE 6 Transient solutions for the isentropic Mach number distributions for the mid-span section; 3 rotor settings. 
Concerning the interaction of the wake with the downstream stator flow field essential features can be predicted in good qualitative agreement with the experiments of Dunker (1983), Figs. 7 and 8 .

\section{(a) experiments}

(Dunker, 1983)

(b)

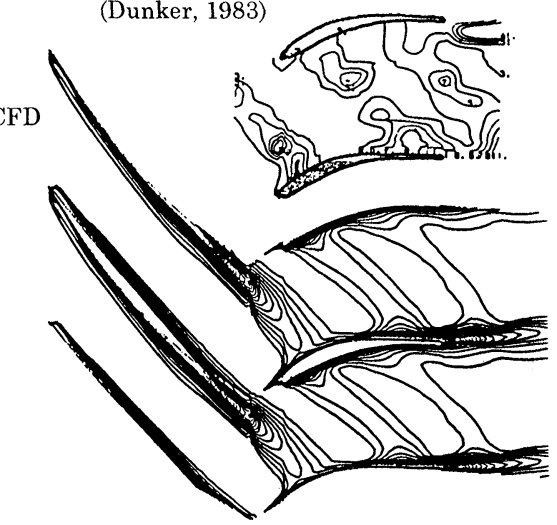

(b) $\mathrm{CFD}$

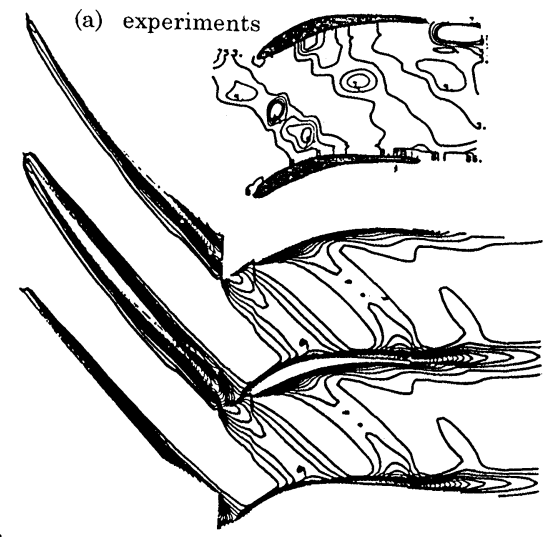

(b) $\mathrm{CFD}$

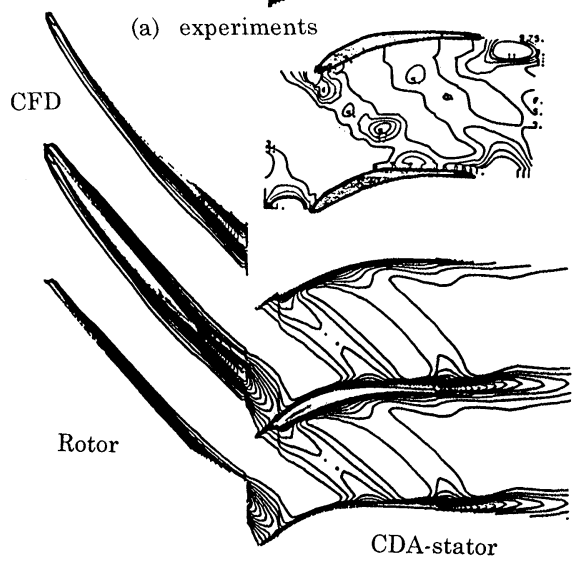

FIGURE 7 Comparison of predicted contours of the turbulent kinetic energy $k$ with measured turbulent intensities (Dunker, 1983). Mass flux: $17.3 \mathrm{~kg} / \mathrm{s}$.
The distributions of the computed turbulent kinetic energy contours disclose similar structures for the corresponding rotor settings, Fig. 7. It is an essential observation that the turbulence intensity
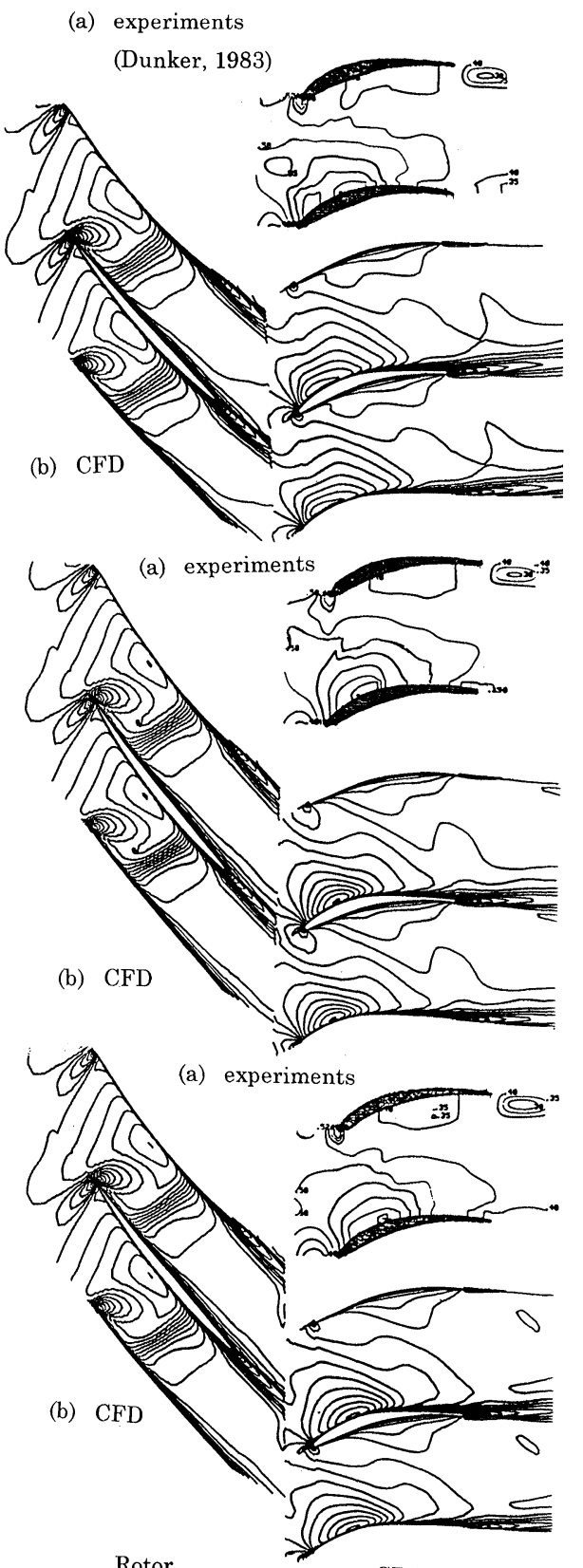

CDA-stator

FIGURE 8 Comparison of predicted Mach number contours with measured velocity contours (Dunker, 1983). Mass flux: $17.3 \mathrm{~kg} / \mathrm{s}$ 
of the wake strongly interacts with the wall boundary layers and create local clusters of high turbulence levels. The traces of the wake can be also found in the relative Mach number distributions and agree fairly well with the measured deformations of the velocity contours, Fig. 8. It can be seen that the velocity fluctuations are more pronounced near the pressure side of the stator which is also reflected by the blade isentropic Mach number graphs previously discussed (Fig. 6). The response of the rotor flow field to the time dependent results is relatively weak.

Interesting pattern of the predicted turbulent eddy viscosities are shown in Fig. 9 for blade sections near mid span and at $75 \%$ span. In

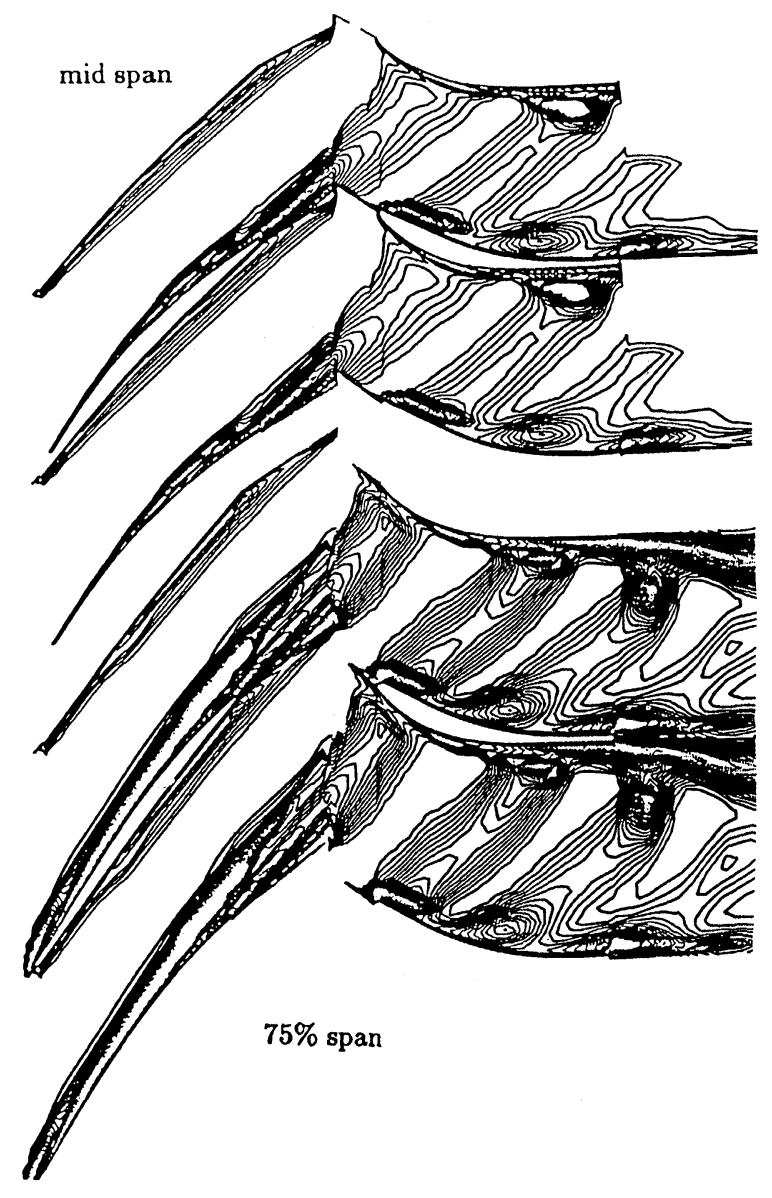

FIGURE 9 Predicted eddy-viscosity contours at mid span and $75 \%$ span sections of the axial compressor. Mass flux: $17.3 \mathrm{~kg} / \mathrm{s}$. particular at the near tip region large domains of high turbulence level are generated in the transonic region of the rotor and the tip leakage flow. The boundary layer of the stator suction side becomes thick and separates. Interesting details are the clusters of strong turbulence intensities close to the blade boundary layers of the stator which are also found in the measured pattern. However, it is difficult to evaluate in how far the predicted eddy viscosities really correspond with the measured turbulence intensities.

\subsection{Computation of Global Blade Forces}

Finally a short look shall be given to the blade forces which are important input parameters for a structural analysis of the airfoils. As expected the amplitudes of the flow induced forces are considerably larger for the stator, Fig. 10. Among the components of the forces, the radial component is the most dominant for the rotor due to the centrifugal forces. The stator is characterized by large axial components and negligible radial load. It is shown that the force distributions become almost periodic after about 3 or 4 rotor passing periods and settle fairly fast for the stator. At present no experiments are available for comparison.

\section{CONCLUDING REMARKS}

In this paper a new numerical scheme is presented to solve time-dependent viscous flow fields in turbomachines. The code has been evolved from a 3-D time-marching scheme and includes a twoequation $k-\epsilon$ turbulence model. For the verification a one-stage transonic compressor was considered which was investigated in detail by Dunker (1983). In order to reduce the computational effort the real configuration was modified by assuming equal blade count for both stators and rotors. Although this assumption can be accepted as an engineering approach, the authors are aware that some properties of the transient interaction inherent with different blade counts get lost in the simplified model. 

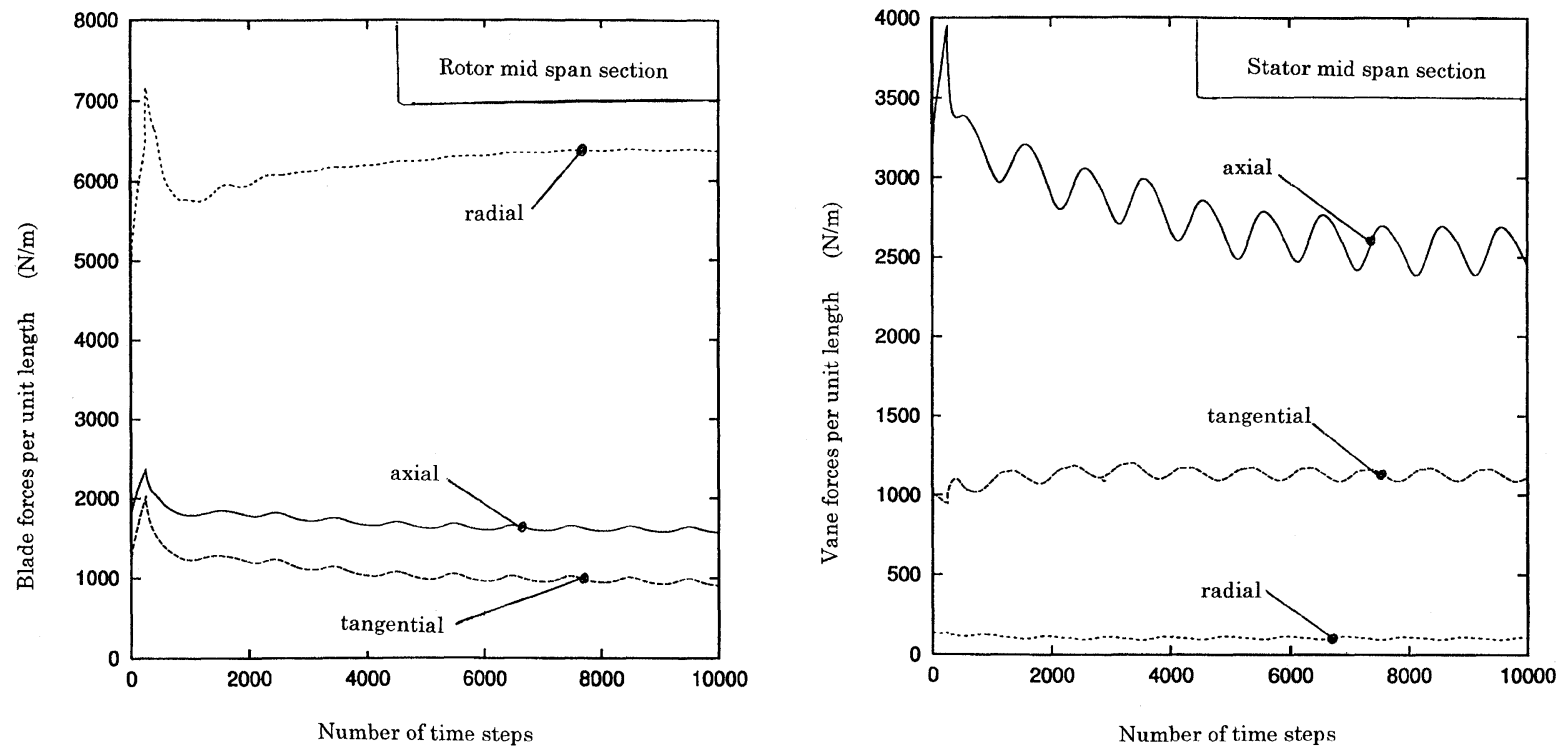

FIGURE 10 Time histories for the absolute force components acting on mid span sections of rotor and stator blades.

The comparison of the results with experiments demonstrates that the solver is capable to predict time-averaged quantities which are of practical interest for the design as well as important features of the interaction of the turbulent wake with the boundary layers along the downstream profiles. It contributes to a more comprehensive investigation of the complex physics in turbomachinery flow fields. Another important property of the solver is the estimation of transient blade loads and the magnitude of amplitudes which can be used as input parameters for a structural analysis at an earlier design stage.

\section{Acknowledgements}

The authors express their gratitude to the Takasago Research and Development Centre of Mitsubishi Heavy Industries, Ltd. for the permission to publish this paper.

\section{References}

Adamczyk, J.J., 1985. Model equation for simulating flows in multistage turbomachinery, ASME 85-GT-226.
Arnone, A. and Benvenuti, E., 1994. Three-dimensional Navier-Stokes analysis of a two-stage gas turbine, ASME 94-GT-88.

Chien, K.Y., 1982. Predictions of channel and boundary layer flows with a low-Reynolds number turbulence model, $A I A A$ Journal, 20, 33-38.

Cho, N.-H., Liu, X., Rodi, W. and Schönung, B., 1993. Calculation of wake-induced unsteady flow in a turbine cascade, ASME Journal of Turbomachinery, 115, 675-686.

Dawes, W.N., 1988. Development of a 3D-Navier-Stokes solver for application to all types of turbomachines, $A S M E$ 88-GT-70.

Dawes, W.N., 1994. A numerical study of the interaction of a transonic compressor rotor overtip leakage vortex with the following stator blade row, ASME 94-GT-156.

Denton, J.D., 1992. The calculation of three-dimensional viscous flow through multistage turbomachines, ASME Journal of Turbomachinery, 114, 18-26.

Dunker, R.J., 1983. Flow measurements in the stator row of a single-stage transonic axial-flow compressor with controlled diffusion stator blades, AGARD CP 351, Paper 23.

Dunker, R.J., Rechter, H., Starken, H. and Weyer, H.B., 1983. Redesign and performance analysis of a transonic axial compressor stator and equivalent plane cascade with subsonic controlled diffusion blades, ASME 83-GT-208.

Eguchi, T. and Wiedermann, A., 1995. Numerical analysis of unstalled and stalled flutter using a Navier-Stokes code with deforming meshes, in Unsteady Aerodynamics and Aeroelasticity of Turbomachines, Eds., Y. Tanida and M. Namba, pp. 237-254, Elsevier.

Gallus, H.E., Zeschky, J. and Hah, C., 1994. Endwall and unsteady flow phenomena in an axial turbine stage, ASME94GT-143.

He, L., 1993. VIB2D, Quasi 3-D unsteady viscous flow method for blade flutter calculation, CUED/A-TURBO/TR.129, University of Cambridge. 
Hodson, H.P., Addison, J.S. and Stepherdson, C.A., 1992. Models for unsteady wake-induced transition in axial turbomachines, Journal de Physique III, 545-574.

Kato, D., Outa, E. and Chiba, K., 1995. A numerical study of propagating stall in 2-D compressor rotor/stator cascades systems, in Unsteady Aerodynamics and Aeroelasticity of Turbomachines, Eds., Y. Tanida and M. Namba, pp. 609624, Elsevier

Miyawaki, T., Miyagawa, K., Wiedermann, A., Watanabe, E. and Seki, N., 1996. Application of numerical simulation for turbomachinery flow analysis (in Japanese), Mitsubishi Juko Giho, 33(4), $274-278$
Rai, M.M., 1987. Unsteady three-dimensional Navier-Stokes simulations of turbine rotor-stator interaction, $A I A A-87$ 2058

Rhie, C.M., Zacharias, R.M., Hobbs, D.E., Sarathy, K.P., Biederman, B.P., Lejambre, C.R. and Spear, D.A., 1994. Advanced transonic fan design procedure based on a NavierStokes method, ASME Journal of Turbomachinery, 116, 291 297.

Wiedermann, A., 1995. CFD-analysis of 3D viscous effects in turbomachinery cascades including tip clearance flow, Proceedings of 1995 Yokohama Gas Turbine Congress, Vol. 1, pp. $127-134$. 


\section{ait \\ ENERGY MATERIALS}

M A N E Y publishing

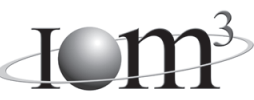

\section{Materials Science \& Engineering for Energy Systems}

Maney Publishing on behalf of the Institute of Materials, Minerals and Mining

The Institute of Materials, Minerals \& Mining

Economic and environmental factors are creating ever greater pressures for the efficient generation, transmission and use of energy. Materials developments are crucial to progress in all these areas: to innovation in design; to extending lifetime and maintenance intervals; and to successful operation in more demanding environments. Drawing together the broad community with interests in these areas, Energy Materials addresses materials needs in future energy generation, transmission, utilisation, conservation and storage. The journal covers thermal generation and gas turbines; renewable power (wind, wave, tidal, hydro, solar and geothermal); fuel cells (low and high temperature); materials issues relevant to biomass and biotechnology; nuclear power generation (fission and fusion); hydrogen generation and storage in the context of the 'hydrogen economy'; and the transmission and storage of the energy produced.

As well as publishing high-quality peer-reviewed research, Energy Materials promotes discussion of issues common to all sectors, through commissioned reviews and commentaries. The journal includes coverage of energy economics and policy, and broader social issues, since the political and legislative context influence research and investment decisions.

\section{CALL FOR PAPERS}

Contributions to the journal should be submitted online at http://ema.edmgr.com

To view the Notes for Contributors please visit: www.maney.co.uk/journals/notes/ema

Upon publication in 2006, this journal will be available via the Ingenta Connect journals service. To view free sample content online visit: www.ingentaconnect.com/content/maney

For further information please contact:

Maney Publishing UK

Tel: +44 (0)113 2497481 Fax: +44 (0)1132486983 Email: subscriptions@maney.co.uk

or

Maney Publishing North America

Tel (toll free): 8662975154 Fax: 6173546875 Email: maney@maneyusa.com

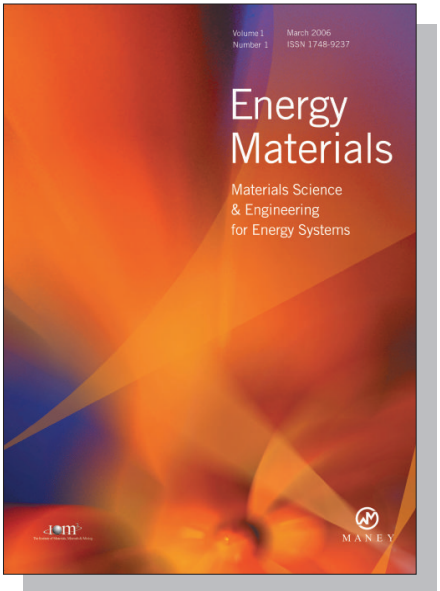

EDITORS

Dr Fujio Abe

NIMS, Japan

Dr John Hald, IPL-MPT, Technical University of Denmark, Denmark

Dr R Viswanathan, EPRI, USA

\section{SUBSCRIPTION INFORMATION}

Volume 1 (2006), 4 issues per year

Print ISSN: 1748-9237 Online ISSN: 1748-9245

Individual rate: $£ 76.00 / U S \$ 141.00$

Institutional rate: $£ 235.00 /$ US $\$ 435.00$

Online-only institutional rate: $£ 199.00 / U S \$ 367.00$

For special $\mathrm{IOM}^{3}$ member rates please email

subscriptions@maney.co.uk

\section{For further information or to subscribe online please visit www.maney.co.uk}



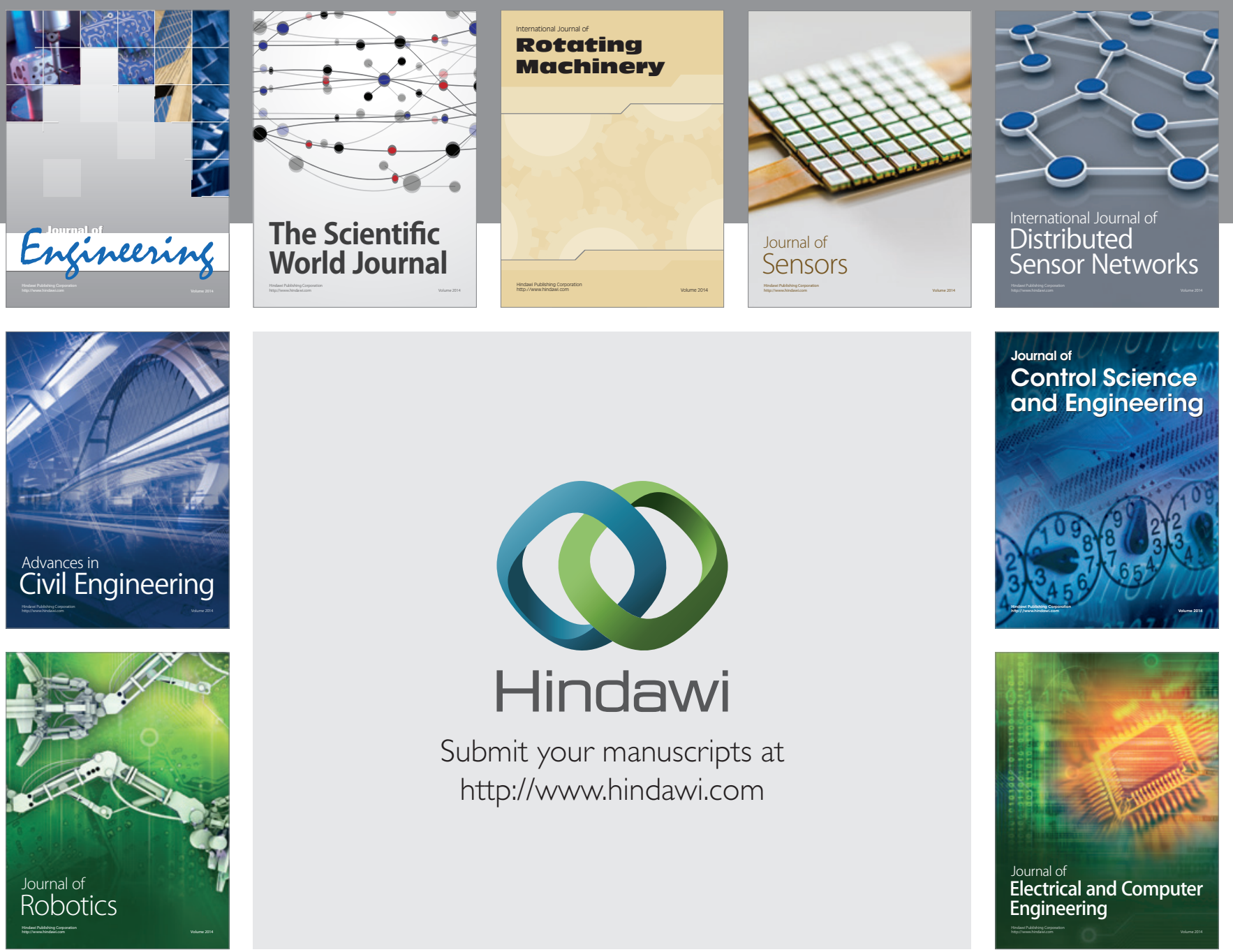

Submit your manuscripts at

http://www.hindawi.com
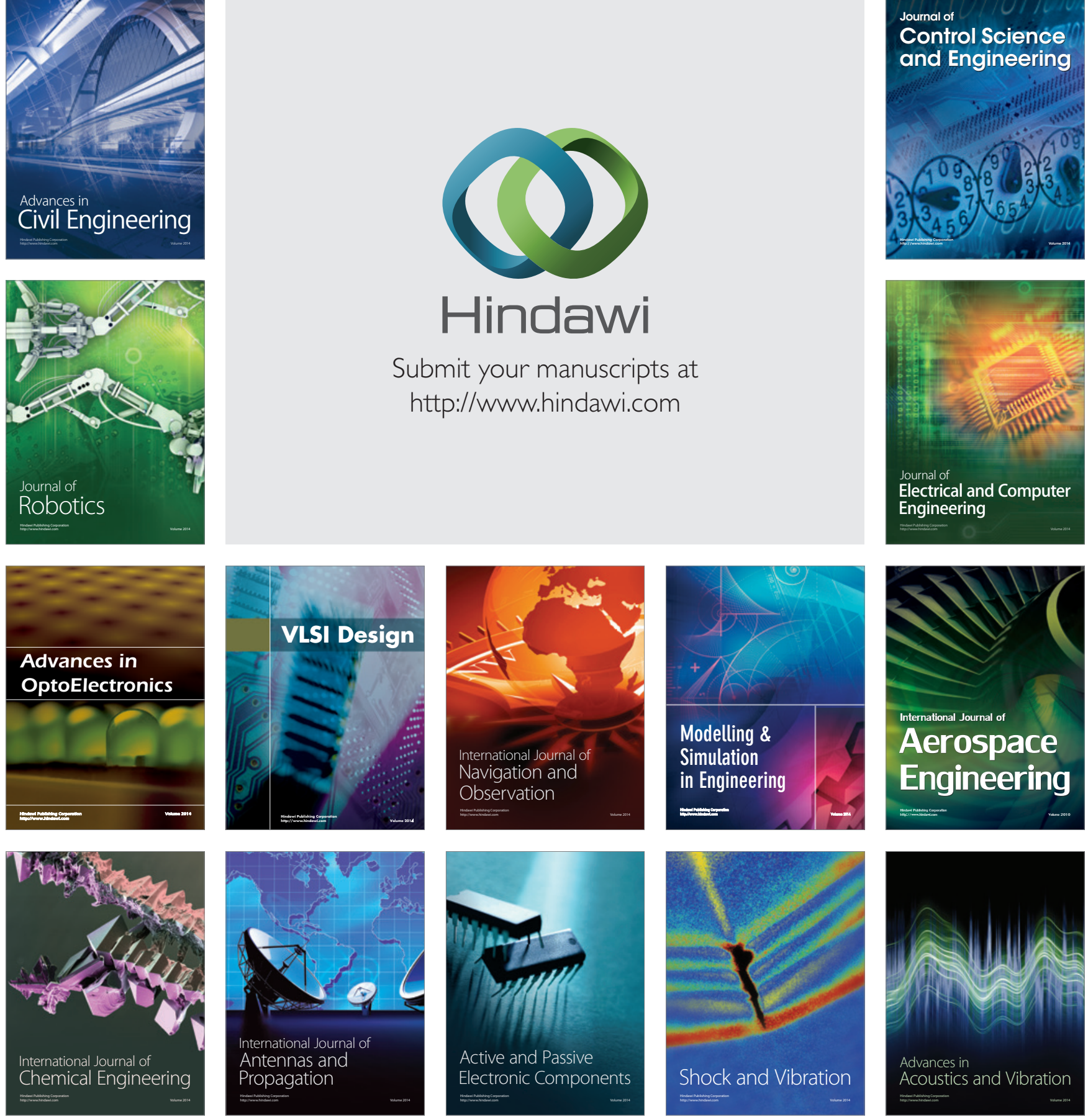